\title{
Paper as a.positive reinforcer for acquisition of a bar press response by the golden hamster
}

PAUL E. JANSEN, University of Florida, Gainesville, Fla. 32601, EDWARD D. GOODMAN, Emory University, Atlanta, Ga., 30322, DENNIS JOWAISAS, University of Florida, Gainesville, Fla. 32601, and B. N. BUNNELL, University of Georgia, Athens, Ga. 30601

Six Golden hamsters (Mesocricetus auratus) learned to depress a lever in order to obtain small strips of paper which were subsequently used in building their nests. $A$ second, yoked control experiment showed that the contingency between the lever press and paper delivery, not a rise in general activity, controlled the response rate.

In a recent theoretical paper Glickman \& Schiff (1967) have proposed that positive reinforcement is best defined at the species-specific level. They contend that the performance of species-typical consummatory acts activate distinguishable neural centers, and that the activation of these centers can be equated with primary positive reinforcement for that species. A reinforcer is broadly defined as anything that increases the probability of occurrence of some class of responses (Kimble, 1961, p. 203). Primary reinforcers are considered to be events which affect the response rate directly, whereas secondary reinforcers influence behavior through association with some known primary reinforcer. Food is an example of a primary reinforcer, while anything reliably paired with food, such as a food dish, could serve as a secondary reinforcer.

Besides food, water, and sex, the term reinforcer has, in recent years, been expanded to include saccharine (Sheffield \& Roby, 1950), various types of sensory stimulation (Kish, 1966), activity (Kagan \& Berkum, 1954), and brain stimulation (Olds \& Milner, 1954). Other novel reinforcers are opportunities to manipulate complex objects (Harlow, 1950), to explore a new environment (Montgomery, 1954), and to dig in sand (King \& Weisman, 1964).

Both male and female golden hamsters exhibit species-specific patterns of nest building activity. When given access to nesting materials at a point remote from the nest site, we have found that hamsters will exert considerable effort in collecting such material and carrying it to the nest (Goodman, Jansen, \& Bunnell, 1967). Data from our laboratories indicate that this response is difficult to satiate, and that the majority of hamsters gather nesting materials in preference to food pellets when both objects are made equally accessible. Although nesting responses are improved at lower ambient temperatures, they persist at temperatures in excess of $80 \mathrm{deg} F$.

\section{SUBJECTS}

In the first experiment, two male and four female golden hamsters (Mesocricetus auratus), approximately 120 days old, were used as Ss. Each hamster was individually housed in a $20 \times 20 \times 20 \mathrm{~cm}$ hardware cloth and wood cage. A guillotine door separated each living cage from a hardware cloth runway $61 \mathrm{~cm}$ long and $7.6 \mathrm{~cm}$ square in cross section.

\section{APPARATUS}

During testing sessions, a paper dispensing apparatus housed in a Plexiglas box (17.8 x $17.8 \times 22.8 \mathrm{~cm}$ high) was placed at the end of the runway. Each time a hamster pressed a bar located in the box, a piece of paper $(2.54 \times 1.27 \mathrm{~cm})$ from a continuous roll was delivered through a slot into the box. The animals could enter and leave the box freely during all phases of testing.

\section{PROCEDURE}

All Ss were given $12 \mathrm{~h}$ of training during which bar pressing was effective in producing paper delivery. Training was followed by $4 \mathrm{~h}$ of extinction where the bar-press/paper-delivery contingency was no longer in effect. Extinction was followed by $2 \mathrm{~h}$ of retraining: Bar pressing again produced paper. With the exception of the first four training sessions which were $1 / 2 \mathrm{~h}$ long, the experiment was carried out in daily $1-h$ sessions.

When a test session began, the guillotine door separating the hamster's home cage from the alley was removed. The Ss typically entered the box within $30 \mathrm{sec}$ after the door was removed. The Ss learned the bar-press/ paper-delivery contingency quickly and became quite proficient at chewing off the strip of paper as it emerged. In hoarding paper, the animals typically inserted it into their cheek pouches; when their pouches were full, they returned to their home cages and depouched the paper. They then returned to the test chamber and began pressingagain.

\section{RESULTS AND DISCUSSION}

\section{Experiment 1}

The results of the first experiment are summarized in Fig. 1. The ordinate shows the mean number of bar presses per hour.
The abscissa shows the last $4 \mathrm{~h}$ of training, $4 \mathrm{~h}$ of extinction, and $2 \mathrm{~h}$ of retraining. During the last four training sessions the hamsters were being reinforced with paper on the average of once every $30 \sec$ (VI 30 schedule) if they responded.

An analysis of variance (repeated measures design) showed that the differences between the response rate during training and extinction was significant at the .01 level $[F(1,5)=34.38]$. As would be expected when comparing the end of training with the progressive extinction sessions, the interaction term was also significant $[F(3,15)=3.39 ; p<.05]$.

Although these results strongly suggested that paper delivery acted as a primary reinforcer for the hamsters, certain features of the apparatus and certain characteristics of the Ss allowed an alternative explanation for the results. In a small open field, almost $50 \%$ of the hamsters' behavior consists of rearing and scratching at the walls of the enclosure (Jowaisas, 1969). This type of behavior in the test chamber results in a large number of bar switch closures even when no contingency has been programmed. If the delivery of paper were to increase the general activity level of the Ss, the average response rates could show increases that would be unrelated to any learning of a bar-press/paper-delivery contingency. A second experiment was performed to test this possibility.

\section{Experiment 2}

Eight naive female hamsters, approximately 100 days old, were placed in the living cages and left for $24 \mathrm{~h}$. On the three succeeding days each $S$ was allowed $1 / 2-h$ access to the box and the baseline rate of nonreinforced bar presses was recorded. After the third session the animals were assigned to either an experimental or a yoked control condition, with the total number of nonreinforced responses of the two groups being approximately equal. The experimental member of each pair was treated in the normal manner: $A$ bar press delivered a strip of paper. For the yoked

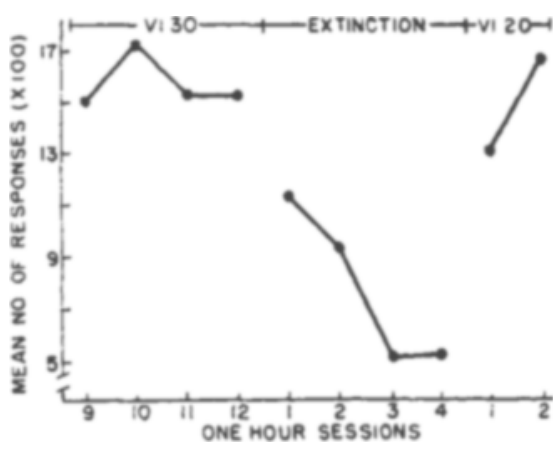

Fig. 1. Average response rates during the last $4 \mathrm{~h}$ of training, the $4 \mathrm{~h}$ of extinction, and the $\mathbf{2} \mathrm{h}$ of retraining. 


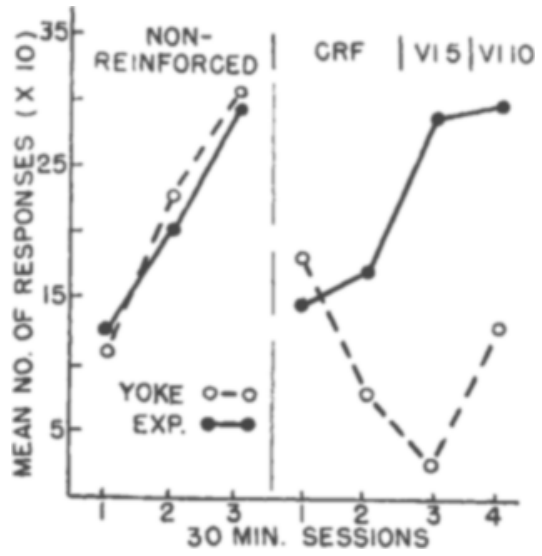

Fig. 2. Average response rates for the yoked control and experimental animals under nonreinforced and reinforced conditions.

partner of the pair no such contingency was in effect. Rather, paper delivery to these Ss depended upon the reinforced responses of their experimental partners. One pair of animals was dropped from the experiment because the experimental $S$ was unable to cut off the paper at the delivery slot and consequently failed to show any evidence of learning. No reason for this aberrant behavior was found.

During the first two sessions when bar responses were followed by paper a continuous reinforcement (CRF) schedule was in effect. It can be seen from Fig. 2 that one of the effects of paper delivery was an initial reduction in bar presses relative to the nonreinforced rate for both groups. This is to be expected because the topography of the paper-cutting response precludes activity in the vicinity of the bar. As the experimental group became adept at cutting off the paper strip their response rate increased and there was a corresponding increase in the number of reinforcements attained. Meanwhile, the yoked animals spent increasing amounts of time in the vicinity of the paper slot and away from the bar. Presumably, this increasing orientation towards the slot is the behavior which is reinforced most often. The difference between the response rates of the two groups during the second CRF session is significant at the .05 level $(t=2.60, d f=4)$.

In the third session reinforcement was delivered on a VI 5-sec schedule. In practice, there is little difference between the CRF and VI 5-sec schedules because the amount of time necessary to cut the paper strip limits the response rate under CRF. In the fourth session, under a VI 10-sec schedule, the bar pressing of the experimental animals was disrupted. After several unreinforced presses it was not uncommon to see an experimental animal leave the box and return to its home cage, rearrange the nesting material already obtained and then return to the test chamber. On VI $10 \mathrm{sec}$ such behavior resulted in reinforcement of the first response emitted after re-entering the box. This often resulted in a temporary increase in leaving the box. As a consequence, Ss received fewer reinforcements during the fourth session than during the third ( 323 vs 423 ). This decrease in the amount of paper delivered to the yoked animals caused a corresponding increase in their response rate. The average interval between reinforcements was longer allowing behavior other than "slot tending" to intervene and to be reinforced. The subsequent rise in activity level resulted in more bar contacts. Nevertheless, the response rates of the two groups were significantly different under both VI 5 and VI $10(t=4.45$ and $t=2.23$, respectively, $\mathrm{p}<.05, \mathrm{df}=4)$.

Two of the pairs were allowed three additional $1 / 2-h$ sessions. The experimental Ss emitted an average of 292 responses per session, while the yoked animals had an average of 98 . In general, the response rates of all the experimental $\mathrm{Ss}$ in the second experiment were comparable to those of animals in the first experiment with equivalent amounts of training.

Because the Ss could leave the test chamber, deviation from strict yoked conditions was possible. To evaluate this possibility, the location of the yoked animals during the delivery of a reinforcement was recorded during several randomly selected 15-min periods. Each pair of Ss was sampled at least once. The yoked animals were present in the test chamber for $86.4 \%$ of 125 reinforcements that were obtained by the experimental animals. Rarely was a yoked $S$ out of the box for two consecutive reinforcements. The sound of the delivery motor appeared to operate as a discriminative stimulus for an immediate return to the test chamber.

In conclusion, the data demonstrate that paper can serve as a potent positive reinforcer for hamsters, and can maintain rates of operant responding comparable to those obtained when food or water is used as a reinforcer. Recent changes in our apparatus design have reduced the freeoperant rate of 10 new Ss to an average of 18 bar presses per hour. These same Ss are now producing 2,000-3,000 responses per hour on a VI 30-sec schedule. We have also found that access to the home cage environment is not critical in maintaining this bar-pressing behavior, although the rates of responding are severely depressed in the typical Skinner box situation where there is no opportunity to "hoard" more paper than fills the animal's cheek pouches.

It may be possible to quantify the behavior of other species which exhibit strong nesting behavior using similar experimental tactics. If, as Glickman \& Schiff (1967) propose, distinguishable neural circuits are responsible for nesting and hoarding behaviors, then the operant paradigm can serve as a useful tool in exploring the physiological aspects of these behaviors.

\section{REFERENCES}

GLICKMAN, S. E., \& SHIFF, B. B. A biological theory of reinforcement. Psychological Review, 1967, 74, 81-109.

GOODMAN, E. D., JANSEN, P. E., \& BUNNELL, B. N. Paper presented at the Psychonomic Society, October 1967

HARLOW, N. F. Learning and satiation of response in intrinsically motivated complex puzzle performance by monkeys. Journal of Comparative \& Physiological Psychology, 1950, 43, 289-294.

JOWAISAS, D. Changes in the open field behavior of female golden hamsters. Psychonomic Science, 1969, 14, 126-127.

KAGAN, J., \& BERKUM, M. The reward value of running activity. Journal of Comparative \& Physiological Psychology, 1954, 47, 108.

KIMBLE, G. A. Hilgard and Marquis' conditioning and learning. New York: Appleton-CenturyCrofts, 1961.

KING, J. A., \& WEISMAN, R. G. Sand digging contingent upon bar pressing in deermice (Peromyscus). Animal Behaviour, 1964, 12, 446-450.

KISH, G. B. Studies of sensory reinforcement. In W. K. Honig (Ed.), Operant behavior: Areas of research and application. New York: AppletonCentury-Crofts, 1966. Pp. 109-159.

MONTGOMERY, $K$. C. The role of the exploratory drive in learning. Journal of Comparative \& Physiological Psychology, 1954, 47, 60-64.

OLDS, J., \& MILNER, P. Positive reinforcement produced by electrical stimulation of septal area and other regions of rat brain. Journal of Comparative \& Physiological Psychology, 1954, 47, 419-427.

SHEFFIELD, F. D., \& ROBY, T. B. Reward value of a non-nutritive sweet taste. Journal of Comparative \& Physiological Psychology, 1950, $43,471-481$.

\section{NOTE}

1. This research was supported, in part, by funds from the Center for Neurobiological Sciences, University of Florida, Grant No. MH 10320-04. 